\title{
Advogando nas ruas: a advocacia nos protestos urbanos no Rio de Janeiro e em São Paulo (2013-2015) ${ }^{1}$
}

Advocating on the streets: advocacy in urban protests in Rio de Janeiro and Sao Paulo (20132015)

\section{Frederico de Almeida² Rodolfo Noronha3}

\begin{abstract}
Palavras-chave: Resumo: $O$ objetivo deste trabalho é apresentar Advocacia de causas;

Advocacia popular; Profissões jurídicas; Protestos; Junho de 2013 resultados de uma pesquisa exploratória sobre o perfil e a atuação de advogadas e advogados durante os protestos urbanos ocorridos no Brasil entre 2013 e 2015. A partir de questões trazidas pela literatura da sociologia das profissões jurídicas a respeito da advocacia de causas, foram realizadas entrevistas com advogados e advogadas que atuaram na defesa de movimentos e manifestantes em protestos no período. A partir da análise das entrevistas, considerando trajetórias pessoais e práticas profissionais, foi possível construir uma tipologia da advocacia em protestos nas duas cidades baseada em dois eixos: a organização profissional, relativa à relação entre advogados e movimentos sociais, e a vinculação profissional, baseada no grau de engajamento dos profissionais na advocacia de causas. Ao final, são apresentadas novas questões de pesquisa sobre a advocacia de causas no Brasil, tendo o protesto como eixo orientador da prática profissional.
\end{abstract}

Keywords: Abstract: This article aims at presenting the results of Cause lawyers; Movement lawyers; Legal professions; Protests; Social movements. an exploratory research on the profile and the practices of lawyers during the urban protests which took place in Brazil between 2013 and 2015. Considering questions presented by the literature on the sociology of legal professions related to cause lawyers, we interviewed lawyers who acted in protests, defending activists and movements, during that period. After analysing the interviews, considering personal trajectories and professional practices, it was

\footnotetext{
${ }^{1}$ Artigo recebido em: 10/2016; artigo aceito em: 03/2016.

2 Instituto de Filosofia e Ciências Humanas da Universidade Estadual de Campinas (IFCH/UNICAMP). E-mail <fnralmeida@gmail.com>.

3 Universidade Federal do Estado do Rio de Janeiro (UNIRIO). E-mail <noronhar@gmail.com>.
} 
possible to construct a typology of protest lawyering in those two cities, based in two axes: professional organization, which includes the relation between lawyers and movements; and professional engagement, based on the degree of professional commitment to causes. After all, it will be presented new research questions on cause lawyers in Brazil, considering protest as a guide of the professional practices.

\section{Introdução}

O objetivo deste trabalho é apresentar resultados de uma pesquisa exploratória sobre o perfil e a atuação de advogadas e advogados durante os protestos urbanos ocorridos no Brasil entre 2013 e 20154. Naquele primeiro momento, atos inicialmente convocados contra 0 aumento de tarifas de transporte público se converteram em grandes movimentos de protesto com agendas e integrantes heterogêneos nos principais centros urbanos do país. É possível identificar, ali, o início de um novo ciclo de protestos (TATAGIBA, 2014), que este estudo busca considerar ao focar a análise na atuação dos mesmos grupos de advogados ao longo do período entre 2013 e 2015, o qual compreende as chamadas jornadas de junho, os protestos contra a Copa das Confederações e contra a Copa do Mundo, além de novos protestos do Movimento Passe Livre contra o aumento da tarifa de transporte em São Paulo no início de 2015.

\section{Advocacia de causas}

A sociologia das profissões jurídicas em diversos países, inclusive no Brasil, tem se debruçado sobre o fenômeno do engajamento de advogadas e advogados em causas e movimentos políticos, sob diferentes perspectivas e denominações: advocacia popular, advocacia de causas coletivas, advocacia de interesse público, advocacia de movimentos, advocacia de direitos humanos, advocacia política etc. Não é nosso objetivo chegar a uma definição precisa de cada uma dessas modalidades de advocacia politicamente engajada, tampouco enquadrar nosso objeto de estudo em uma ou outra modalidade. Ao contrário, a pluralidade e a eventual confusão de denominações de um

\footnotetext{
${ }^{4}$ Os dados relativos a São Paulo foram coletados, em parte, no âmbito do projeto de pesquisa "Conflito político e sistema de justiça: a judicialização criminal dos protestos urbanos em São Paulo (2013-2015)", financiado pela Fundação de Amparo à Pesquisa do Estado de São Paulo (FAPESP) (processo no 2015/00255-4); os relativos ao Rio de Janeiro, no âmbito dos projetos de Ensino "Novas perspectivas da Sociologia Jurídica e a democratização do acesso à Justiça", de 2015, e "Sociologia e profissões jurídicas", de 2016, no programa de monitoria da Universidade Federal do Estado do Rio de Janeiro (UNIRIO).
} 
mesmo objeto aparente ${ }^{5}$ reforçam nossa opção pelo conceito de advocacia de causas, por seu conteúdo menos dependente do sentido de engajamento político de advogados ("populares" ou defensores do "interesse público") e, também, por superar a qualificação política da advocacia simplesmente a partir de uma oposição, recorrente nessa literatura, entre clientes individuais e causas coletivas.

Dessa forma, em nosso estudo específico sobre os advogados atuantes nos protestos urbanos nas cidades de São Paulo e Rio de Janeiro a partir de 2013, buscaremos responder a algumas das questões colocadas por essa literatura, apesar de suas diferenças conceituais e metodológicas: qual a "vocação"6 histórica da advocacia em relação à política? Quando se pode dizer que advogados atuam politicamente? O que torna possível sua atuação coletiva? O que os motiva? Quais são suas estratégias, táticas e valores políticos (HALLIDAY, 1999)? Quais as trajetórias pessoais e profissionais desses advogados e as visões de mundo a elas associadas (JUNQUEIRA, 2002; SCHEINGOLD, 1988)? Que tipo de práticas eles promovem, e como podemos compreendê-las em termos de transformação ou conservação da ordem política e jurídica e de inovações de serviços jurídicos? Quais as relações que esses profissionais estabelecem com seus clientes, em termos de protagonismo político e confronto entre saberes (ALMEIDA, 2016a; CAMPILONGO，2000; CARLET， 2015; JUNQUEIRA, 1996; SÁ E SILVA, 2012)?

Ao buscarmos responder questões trazidas por diferentes abordagens e conceituações da advocacia de causas, evitamos a denominação prévia de nosso objeto a partir de uma dessas abordagens, ao mesmo tempo em que colocamos sob crítica e análise a própria pluralidade de definições e manifestações desse tipo de engajamento profissional. Essas denominações diversas extrapolam o debate teórico da sociologia do direito e das profissões jurídicas para se projetarem nas práticas e identidades profissionais e nos conflitos internos aos campos jurídicos, em grande parte pela lógica de exportação, importação e adaptação de modelos político-profissionais (ENGELMANN, 2006a; SÁ E SILVA, 2012). Isso nos obriga a tomá-las como elementos de análise a serem verificados nos dados de nossa

5 Em seu artigo sobre a advocacia popular em uma realidade latinoamericana, por exemplo, Vértiz (2013) traduz o termo "advogados populares" para o inglês como "cause lawyers"; já Sá e Silva (2012), preocupado justamente em entender a multiplicidade de modelos e identidades profissionais, traduz "advogados populares" como "people's lawyers". Carlet afirma que "a advocacia popular é conhecida também como 'advocacia em direitos humanos', 'advocacia ativista' ou ainda 'advocacia alternativa'" (2015, p. 379). McCann e Silverstein (1998) utilizam indiscriminadamente os termos "cause lawyers" e "movement's lawyers" como equivalentes.

6 Vocação aqui entendida não como "chamado divino", sentido que normalmente lhe é atribuído, mas como representação de papel funcional construído ao longo do tempo. 
pesquisa empírica, como fatores estruturantes de divisões políticas, identidades profissionais e práticas entre grupos de advogados, e não apenas como categorias teóricas de análise apriorística do nosso objeto.

Portanto, desse diálogo com a literatura sobre advocacia popular, advocacia de causas coletivas e de movimentos sociais, advocacia de interesse público etc., interessa-nos menos as denominações dos tipos de advocacia de causas e mais as características e dilemas gerais e específicos empiricamente verificados, que tendem a diferenciar essas modalidades de engajamento profissional de advogados entre si e as formas convencionais ou "tradicionais" de advocacia. Somente a partir dessas diferenciações verificadas "em ação" (tendo o ciclo de protestos de 2013 como referência), buscando suas motivações, suas trajetórias, suas relações com causas e clientes, suas práticas profissionais, suas percepções sobre o direito e a política, e nos limites das expressões de advocacia política presentes no contexto por nós analisado, é que poderemos avançar em um tipologia de trajetórias e práticas útil ao nosso objeto.

\section{Metodologia}

Foram entrevistados(as) oito advogados(as) em São Paulo e oito no Rio de Janeiro. Esses(as) profissionais tiveram diferentes tipos de engajamento no período analisado. A seleção de entrevistados foi feita por amostragem por conveniência e pela técnica "bola de neve"7, utilizando, para isso, em um primeiro momento, as redes pessoais dos pesquisadores envolvidos, para depois seguir as indicações dos próprios atores do campo.

\footnotetext{
${ }^{7} \mathrm{~A}$ amostragem por conveniência é aquela na qual os elementos da população que se pretende estudar são selecionados pela proximidade e/ou pela facilidade de acesso do próprio pesquisador. $\mathrm{Na}$ presente pesquisa, recorremos tanto a advogados cuja prática profissional em protestos era objeto de divulgação via redes sociais (sendo este o meio do contato inicial), quanto a advogados com os quais mantínhamos algum grau de contato pessoal ou profissional anterior (sendo estes profissionais acionados como informantes ou entrevistados). A amostragem por "bola de neve" acontece quando um respondente indica outros possíveis respondentes da pesquisa. Adotamos esse procedimento ao buscar indicações junto aos primeiros entrevistados de outros advogados que também atuaram nos protestos e que poderiam ser entrevistados. Mesmo cientes dos vieses que esse tipo de amostragem pode produzir - especialmente no que se refere à configuração de redes de relacionamento pessoal e profissional que podem ocultar ou distorcer as redes de relações e de organização profissional que estruturam a população de advogados de causas atuantes em protestos nas cidades e períodos selecionados -, acreditamos ser a escolha justificada pelo caráter exploratório da pesquisa. Para uma utilização de técnicas semelhantes de amostragem na pesquisa sobre advogados, ver Etienne (2005).
}

Caderno Eletrônico de Ciências Sociais, Vitória, v. 4, n. 2, pp. 5-28, 2016 
Em São Paulo, foram contatados inicialmente os advogados participantes do coletivo Advogados Ativistas (AA), dada sua forte projeção e fácil identificação em redes sociais. Posteriormente, em conversa com uma advogada de movimentos sociais que teve atuação secundária nos protestos, foram identificados e contatados outros advogados que atuaram na defesa de ativistas do Movimento Passe Livre (MPL). Ambos os grupos forneceram contatos de outros advogados que poderiam ser entrevistados. A partir dessas conexões, conseguimos alcançar uma amostra de advogados e práticas profissionais diversificada, como um coletivo de advogados criado por ocasião dos protestos de junho de 2013, grupos já atuantes na assessoria a movimentos sociais antes de junho de 2013 e membros da Defensoria Pública do estado.

No Rio de Janeiro, o primeiro advogado entrevistado vinha de longo trajeto de militância, possuía ligações com o coletivo Habeas Corpus (HC) - que reuniu, ao longo de 2013, a maior parte das pessoas que advogaram nas manifestações, segundo ele -, e ajudou a fundar o Coletivo de Advogados do Rio de Janeiro (CDA/RJ), ligado à Caixa de Assistência ao Advogado do Rio de Janeiro (CAARJ) e à seção estadual da Ordem dos Advogados do Brasil (OAB/RJ). A partir dele, foi possível chegar a outros advogados e advogadas com ligações semelhantes (embora diversas). De outro lado, foram procuradas advogadas independentes que participaram dos mesmos coletivos no início, mas que seguiram outras direções quando da criação do CDA/RJ, - que tornou possível acessar outra "linha" de atuação nas manifestações.

Para manter o anonimato dos entrevistados, seus nomes foram substituídos por códigos, compostos pela sigla do estado de atuação ("SP" ou "RJ") e pelo número de sua posição na ordem cronológica das entrevistas. Algumas entrevistas foram realizadas em conjunto, com mais de um respondente. Eis, portanto, a relação dos profissionais entrevistados, seguida de uma breve descrição de suas atuações nos protestos:

- Advogados SP1 e SP2: advogados do coletivo Advogados Ativistas; entrevista realizada em 22 de agosto de 2014.

- Advogado SP3: advogado colaborador do Movimento Passe Livre; entrevista realizada em 3 de setembro de 2014.

- Advogados SP4 e SP5: defensores públicos, membros do Núcleo Especializado da Situação Carcerária da Defensoria Pública do Estado de São Paulo; entrevista realizada no dia 23 de setembro de 2014.

- Advogado SP6: coordenador da ONG Conectas Direitos Humanos; entrevista realizada no dia 23 de outubro de 2015.

- Advogado SP7: advogado do Movimento Passe Livre; entrevista realizada em 11 de novembro de 2015.

- Advogado SP8: advogado colaborador do Movimento Passe Livre; entrevista realizada em 3 de maio de 2016. 
- Advogado RJ1: advogado do Coletivo de Advogados; entrevista realizada em 7 de abril de 2015.

- Advogada RJ2: advogada independente (em junho de 2013, ainda era estudante; hoje, advogada do Movimento dos Trabalhadores Sem Teto); entrevista realizada em 15 de abril de 2015.

- Advogado RJ3: advogado do Coletivo de Advogados; entrevista realizada em 15 de abril de 2015.

- Advogada RJ4: advogada independente; entrevista realizada em 6 de maio de 2015.

- Advogada RJ5: advogada independente; entrevista realizada em 22 de junho de 2015.

- Advogadas RJ6, RJ7 e RJ8: advogadas do Centro de Assessoria Popular Mariana Crioula; entrevista realizada em 29 de junho de 2015.

Foram realizadas entrevistas semiestruturadas, baseadas em roteiro de questões básicas igualmente aplicado aos entrevistados de São Paulo e do Rio de Janeiro, após teste do instrumento nas primeiras entrevistas de São Paulo. As entrevistas foram analisadas e codificadas, contando com auxílio de um software de análise qualitativa ${ }^{8}$, buscando-se identificar e interpretar seu conteúdo a partir das seguintes variáveis (detalhadas, eventualmente, em códigos mais específicos):

- Trajetória pessoal e familiar

- Trajetória acadêmica

- Trajetória profissional

- Socialização política

- Atuação nos protestos

- Forma organizacional/operacional para atuação em protestos

- Aprendizado decorrente da atuação em protestos

- Redes de relações pessoais/profissionais

- Relações com outros grupos ou tipos de advocacia de causas no contexto dos protestos

- Outras atuações em advocacia de causas

- Percepções sobre as instituições do sistema de justiça e segurança pública

- Relações com movimentos sociais

- Relações com a mídia

- Relações entre técnica jurídica e ação política

- Percepções sobre junho de 2013

\footnotetext{
${ }^{8}$ Foi utilizado o software Atlas.ti (versão 7); para maiores informações, ver http://atlasti.com/. Para uma avaliação das ferramentas do tipo CAQDAS (Computing Assisted Qualitative Data Analysis Software), incluindo o citado software, ver Cisneros Puebla (2003).
} 
A partir dessa codificação, a análise das entrevistas buscou identificar as trajetórias, perfis profissionais, formas de organização e atuação em protestos, além das relações mais amplas entre advocacia e movimentos sociais e entre direito e política verificáveis nesses dois contextos.

\section{Trajetórias pessoais, acadêmicas e profissionais}

A tabela abaixo apresenta os elementos de trajetórias pessoais, acadêmicas e profissionais dos advogados entrevistados, agrupados por local de atuação nos protestos.

Tabela 1. Distribuição de entrevistados de acordo com as trajetórias pessoais, acadêmicas e profissionais, por cidade de atuação (Brasil, 2013-2016)

\begin{tabular}{|l|l|l|l|}
\hline & $\begin{array}{l}\text { Advogados } \\
\text { RJ }\end{array}$ & $\begin{array}{l}\text { Advogados } \\
\text { SP }\end{array}$ & TOTAL \\
\hline Ensino médio privado & 7 & 7 & 14 \\
\hline Ensino médio público & 1 & 1 & 2 \\
\hline Faculdade privada & 4 & 6 & 10 \\
\hline Faculdade pública & 4 & 2 & 6 \\
\hline Movimento estudantil & 6 & 5 & 11 \\
\hline Pós-graduação & 8 & 4 & 12 \\
\hline Advogados na família & 3 & 1 & 4 \\
\hline Advocacia privada & 3 & 4 & 7 \\
\hline Assistência jurídica universitária & 3 & 2 & 5 \\
\hline Empresas & 3 & 1 & 4 \\
\hline Órgãos públicos & 3 & 5 & 8 \\
\hline Escritório próprio & 1 & 3 & 4 \\
\hline $\begin{array}{l}\text { Outras atuações anteriores em advocacia de } \\
\text { causas }\end{array}$ & 6 & 6 & 12 \\
\hline Total de entrevistados & 8 & 8 & 16 \\
\hline
\end{tabular}

Fonte: Elaborado pelos autores.

\section{a) Trajetórias acadêmicas}

Predominam em ambos os grupos egressos do ensino médio privado; os únicos entrevistados que cursaram ensino médio público foram um dos defensores públicos entrevistados em São Paulo (Advogado SP5), que na verdade é originário do Rio de Janeiro e cursou o tradicional Colégio Pedro II, e um dos advogados do Rio de Janeiro, também originário do mesmo colégio federal.

No que se refere ao ensino superior, a tendência se mantém: em São Paulo, predominam egressos de cursos de direito oferecidos por instituições privadas, com destaque para a Pontifícia Universidade Católica de São Paulo (Advogados SP3, SP6 e SP8) e a Universidade Presbiteriana Mackenzie (Advogados SP2 e SP7), seguidas das Faculdades Armando Álvares Penteado (Advogado SP1). Os egressos de universidades públicas vêm da Universidade de São Paulo (Advogado SP4) e da Universidade Estadual do Rio de Janeiro (Advogado SP5). No Rio de Janeiro, a Pontifícia Universidade Católica 
do Rio de Janeiro esteve presente na formação de três deles (Advogados RJ4, RJ5 e RJ6), e a Universidade Federal Fluminense na de outros dois (Advogadas RJ7 e RJ8), sendo o mesmo o número de egressos de instituições públicas e de instituições privadas.

Em relação a estudos de pós-graduação, eles são mais predominantes entre os advogados do Rio de Janeiro, não só em termos quantitativos (número de advogados titulados), mas também qualitativos, já que, nesse grupo, predominam estudos de pósgraduação stricto sensu, ao passo que, entre os advogados paulistas, predominam cursos de especialização em direito penal econômico, além de um mestrado em andamento em sociologia. Há indícios de que, talvez no Rio, as redes pelas quais esses advogados e advogadas circulam passem também pelas universidades; as três advogadas do Centro de Assessoria Popular Mariana Crioula afirmaram que a busca pela universidade foi mais do que uma opção pessoal, mas uma estratégia de ocupação de espaços e de desenvolvimento de atividades, como projetos de pesquisa e extensão. Também não podemos descartar a hipótese de investimento pessoal em pósgraduação e na interdisciplinaridade (há duas advogadas do Rio de Janeiro com formações também em áreas diferentes do direito) como estratégia de construção de capitais políticos em trajetórias profissionais alternativas no campo jurídico brasileiro (ENGELMANN, 2006b).

Em ambos os grupos, contudo, predominam trajetórias típicas das posições superiores do campo jurídico brasileiro, conforme analisadas por Almeida (2010; 2012): passagem pelo ensino médio privado como condição para o acesso ao ensino superior público; graduação em direito em instituições públicas ou privadas anteriores à massificação do ensino do direito (com destaque para as universidades católicas, entre as privadas); valorização dos títulos de pós-graduação como título distintivo em um mercado profissional saturado pela massificação do diploma de bacharel; presença residual do recrutamento familiar endógeno, caracterizado pela presença de advogados na família (embora em menor escala - apenas em 3 das 16 entrevistas aparecem familiares atuando no campo da advocacia, pública ou privada).

\section{b) Socialização política}

A participação no movimento estudantil nos cursos superiores de direito também é uma variável importante para se compreender as relações entre juristas e política no Brasil (ALMEIDA, 2010). Na presente pesquisa, em ambos os grupos, ela se configura como um espaço de socialização política, de formação de visões de mundo sobre o direito e a política e de formação de redes de relacionamento pessoais e profissionais, as quais seriam posteriormente ativadas na advocacia de causas e na atuação nos protestos. 
Nesse sentido, veja-se a narrativa do Advogado RJ1 acerca do papel do movimento estudantil em seu engajamento na advocacia de causas:

\begin{abstract}
Mas fui de discussão do Centro Acadêmico, que era do Partido Comunista [...] durante a graduação, comecei a atuar, entrei no movimento negro, que foi a CEAP [Centro de Articulação das Populações Marginalizadas], e ali eu... [...] eu entrei como voluntário, mas em duas semanas eu já fui entrevistado para ser estagiário de Direito. Então eu acabei nem... nem posso dizer que eu fui voluntário lá, que fui militante lá, porque eu não fui. Porque eu fiquei... só conhecia a ONG, me aproximei e aí já abriu imediatamente depois a vaga de estagiário [...], era um movimento negro com crianças e adolescentes; e já fui para o movimento de mulheres; depois... eh... LGBT; depois pessoas com deficiência, liberdade religiosa e essa é minha trajetória. (Entrevista com Advogado RJ1).
\end{abstract}

Veja-se, também, o depoimento do Advogado SP7, que demonstra a importância das relações construídas no movimento estudantil para a construção de redes de profissionais colaboradores da advocacia para o MPL nas manifestações de junho de 2013 e janeiro de 2015:

Foi uma questão bastante pessoal, mas tinha também uma questão política. Eu, particularmente, chamei... grande parte das pessoas que eu chamei, por exemplo, são pessoas que fizeram parte do... do meu movimento estudantil, então, que eu tinha confiança política. (Entrevista com Advogado SP7).

Porém, além do movimento estudantil, a pesquisa identificou outras experiências de socialização política entre advogados de causas atuantes nos protestos. Uma delas é a própria militância em direitos humanos, na qual o papel de advogado de movimentos muitas vezes se confunde, ele mesmo, com uma forma de militância pessoal e de formação política. Esse parece ser o caso do advogado SP7, do advogado RJ1 e das advogadas RJ6, RJ7 e RJ8. Outra forma possível de socialização política identificada foi a de novos movimentos e novas formas de ativismo, como o Ocupa Sampa (inspirado no Occupy Wall Street), do qual participou o advogado SP1, e o próprio ativismo de junho de 2013, do qual participaram, inicialmente como militantes (mais do que como advogados), esse mesmo advogado paulista, as advogadas RJ3, RJ4 e RJ5, e o advogado RJ2. Nesses casos, mais do que mera participação, o ativismo do tipo "occupy" e "junho de 2013" tiveram o papel de despertar para a ação política e para a articulação de redes de ativismo, na narrativa daqueles entrevistados ${ }^{9}$.

$\mathrm{Na}$ faculdade não fiz parte de nada [...] do grêmio, nada. [...] Depois, quando acabou a faculdade, que foi 2011 aí com o Ocupa Sampa, foi quando eu me envolvi com esses... com

${ }^{9}$ Embora o advogado RJ2 já possuísse uma atuação política (vale lembrar que a entrevista foi realizada na sede do Diretório Municipal do Partido dos Trabalhadores), ele narrou sua entrada na advocacia de protestos como consequência de situações que acompanhou como manifestante - segundo ele, de "bermudas e camisa de time de futebol". 
esse pessoal. Na época não tinha nenhum coletivo grande de nome articulando como... como hoje tem. Ou não eram famosos. Os coletivos que tem hoje, grandes e pequenos, famosos ou não, têm alguém dessa época de 2011. Esse... esse cenário aí do Ocupa foi o... foi da onde brotou a galera que, hoje, a gente vê na linha de frente de diversos coletivos. Mas na época não tinha nada muito estruturado - dessa minha experiência, assim. Então não era de nenhum coletivo, mas essa galera formou uma rede de contatos que durou 2 anos para 2013 você ver o pessoal estruturando frentes, assim. Então eu não fiz parte de nenhum coletivo na época, formalizado, mas eu sempre conheci o pessoal que hoje faz parte. (Entrevista com Advogado SP1).

\section{c) Experiências com a advocacia de causas}

Associada a essa questão está, também, a atuação em assessoria jurídica universitária, seja na forma de "assessoria jurídica popular", na qual em geral há projetos de extensão para assessoria coletiva a movimentos ou demandas sociais organizados, seja no formato de "escritórios-modelos", nos quais predomina a assistência judiciária individual. Como se vê na tabela acima, cinco dos entrevistados atuaram em algum tipo de serviço como esse quando estudantes, sendo três no Rio de Janeiro, e dois em São Paulo.

No caso de profissionais do Rio de Janeiro, a passagem por experiências universitárias de assessoria jurídica popular parece ter maior relevância qualitativa do que as experiências relatadas por advogados paulistas (do tipo escritório-modelo, com foco na assistência judicial individual), seja pela formação política e profissional para a advocacia de causas, seja pela construção de redes de relacionamentos com outros profissionais e com movimentos sociais. Nesse aspecto, veja-se o depoimento da Advogada RJ6:

Acho que a extensão já tem um pouco esse caráter, né, da... assessoria popular. No projeto de extensão, acho que foi a primeira vez que eu conheci a [Advogada RJ7], que a [Advogada RJ7] já era advogada do MST [Movimento dos Trabalhadores Rurais Sem Terra], eh... em um projeto de extensão que a gente tinha, que era um projeto interdisciplinar de (...) com Direito, Sociologia, Geografia. Enfim, era um grupo grande, fez um trabalho bem interessante no assentamento que estava tendo um conflito socioambiental com a reserva biológica, e aí eu conheci a [Advogada RJ7], eu já conheci a [Advogada RJ8] também do movimento estudantil, mas a gente não era muito próxima. Eh... e aí começaram, a partir dessa relação também, a [cita outra advogada, não entrevistada] que começou a fazer pesquisa comigo, começaram a fazer umas reuniões em Niterói, da Renap [Rede Nacional de Advogados e Advogadas Populares]. E aí chamaram a gente, eu comecei a participar das reuniões.

No caso dos advogados de São Paulo, é preciso destacar que, entre as passagens por órgãos públicos contabilizadas na tabela acima, predominam estágios na assistência jurídica gratuita prestada pela Defensoria Pública do estado (quatro dos advogados entrevistados). Podemos considerar que, somadas as passagens por escritórios- 
modelos universitários, essas experiências pela Defensoria Pública exercem, na trajetória profissional dos advogados de São Paulo, o papel de formação para a advocacia de causas que a assessoria jurídica popular exerce na trajetória de advogados do Rio de Janeiro. Isso é reforçado se considerarmos o histórico de relações com movimentos sociais e causas coletivas que ocorrem desde o início da recente institucionalização do órgão em São Paulo, bem como a importância de sua atuação nos protestos de junho de 2013 em diante. Além disso, é interessante notar como essa atuação se difere do papel hesitante da Defensoria Pública no Rio de Janeiro em relação aos protestos elementos que serão analisados mais à frente.

\section{d) Perfis profissionais}

Ainda no que se refere a trajetórias profissionais, verifica-se a diversidade de trajetórias, ao mesmo tempo em que se constata a reprodução de percursos bastante típicos da profissão jurídica: passagens pela advocacia privada, abertura de escritório próprio, experiência em órgãos públicos judiciais ou administrativos. Essas trajetórias um tanto comuns devem, contudo, ser relativizadas pela situação profissional dos advogados entrevistados no momento da pesquisa, de acordo com o papel que a advocacia de causas exerce em sua situação profissional naquele momento.

No Rio de Janeiro, cinco (advogados RJ1, RJ3, advogadas RJ6, RJ7 e RJ8) dos oito entrevistados mantêm como atuação principal algum tipo de advocacia de causas, enquanto os demais (advogados RJ2, RJ4 e RJ5) mantêm outras atividades profissionais "regulares", ao lado de uma atuação mais ou menos intensa na advocacia de causas (sendo que a advogada RJ4 tem, no trabalho de tradutora, sua atividade principal, não exercendo advocacia, a não ser a de causas, e de maneira eventual). Em São Paulo, quatro (advogados SP4, SP5, SP6 e SP7) dos sete entrevistados mantêm atividade principal em algum tipo de advocacia de causas, sendo que os demais mantêm esse tipo de engajamento profissional de forma eventual. A advogada RJ2 tem como atividade principal a advocacia em escritório, enquanto atua como assessora de movimento social; vale ressaltar que, no caso dessa advogada, a advocacia de causas se inicia bem depois de junho de 2013.

\section{Organização e vinculação profissional}

Esse último aspecto das trajetórias profissionais nos leva a um resultado importante da pesquisa sobre a advocacia nos protestos recentes. Combinando a identificação que fizemos dos perfis profissionais, de um lado, com as formas de organização profissional e os níveis de engajamento nos protestos, de outro, a leitura e a codificação das entrevistas nos permitiram distinguir dois eixos de análise: o da organização profissional, relacionado à forma como os advogados se organizam em suas relações com os movimentos no momento dos protestos, e o da vinculação profissional, referente aos 
seus diferentes graus de engajamento na assistência jurídica a movimentos e manifestantes em contexto de protestos. Esses eixos estão representados no diagrama 1 , abaixo, com o posicionamento dos entrevistados nos quatro quadrantes.

Diagrama 1. Posição dos entrevistados de acordo com sua organização profissional e sua vinculação profissional (Brasil, 2013-2015)

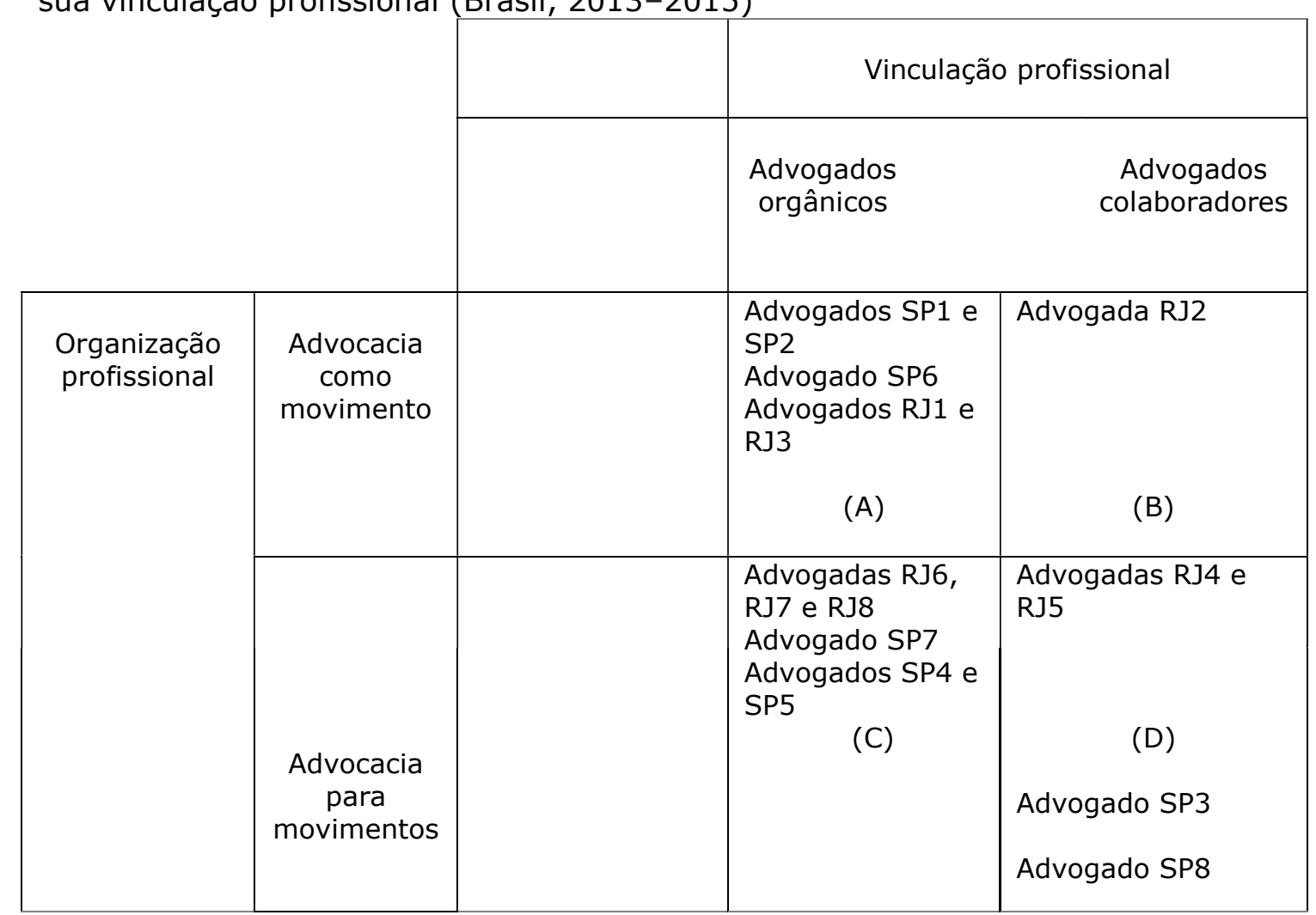

Fonte: Elaborado pelos autores.

No primeiro eixo, podemos distinguir os advogados entre uma organização da advocacia como movimento - quando a atividade da advocacia de causas se assume como uma forma de ativismo político com forma organizacional própria, como organização, rede ou coletivo - e uma organização da advocacia para movimentos - quando a advocacia de causas é exercida como atividade que não se identifica como uma forma de ativismo político, e se coloca em caráter secundário e subordinado ao ativismo político protagonizado pelos movimentos sociais. ${ }^{10}$

No segundo eixo, diferenciamos os advogados orgânicos, aqueles integral ou predominantemente dedicados à advocacia de causas, dos

${ }^{10}$ Agradecemos à sugestão de classificação da organização profissional dos advogados estudados feita por Roberto Fragale e por Fernando Fontainha nos comentários ao paper com resultados parciais dessa pesquisa apresentado no Grupo de Trabalho "Instituições judiciais, agentes e repercussão pública" do $39^{\circ}$ Encontro Anual da Associação Nacional de Pós-graduação e Pesquisa em Ciências Sociais (ALMEIDA; NORONHA, 2015). 
advogados colaboradores, aqueles com dedicação eventual à advocacia de causas, em geral de maneira subordinada aos (ou coordenada pelos) advogados orgânicos. ${ }^{11}$ Se refizermos a análise de elementos de trajetórias do tópico anterior (sintetizada na tabela 1, acima), temos a seguinte distribuição (tabela 2 ):

Tabela 2. Distribuição dos entrevistados de acordo com as trajetórias profissionais, por grupo de advocacia (Brasil, 2013-2015)

\begin{tabular}{|c|c|c|c|c|}
\hline & $\begin{array}{l}\text { Orgânicos } \\
\text { da } \\
\text { advocacia } \\
\text { como } \\
\text { movimento }\end{array}$ & $\begin{array}{c}\text { Colaboradores } \\
\text { da advocacia } \\
\text { como } \\
\text { movimento }\end{array}$ & $\begin{array}{l}\text { Orgânicos } \\
\text { da } \\
\text { advocacia } \\
\text { para } \\
\text { movimentos }\end{array}$ & $\begin{array}{c}\text { Colaboradores } \\
\text { da advocacia } \\
\text { para } \\
\text { movimentos }\end{array}$ \\
\hline Advocacia privada & 2 & 1 & 2 & 4 \\
\hline $\begin{array}{ll}\text { Advogados na } \\
\text { família }\end{array}$ & 1 & 2 & 0 & 1 \\
\hline $\begin{array}{l}\text { Assistência } \\
\text { judiciária } \\
\text { universitária }\end{array}$ & 0 & 0 & 4 & 1 \\
\hline Empresas & 1 & 2 & 2 & 0 \\
\hline $\begin{array}{ll}\text { Ensino } & \text { médio } \\
\text { privado } & \end{array}$ & 4 & 2 & 5 & 3 \\
\hline $\begin{array}{l}\text { Ensino médio } \\
\text { público }\end{array}$ & 0 & 0 & 1 & 0 \\
\hline Escritório próprio & 2 & 0 & 0 & 2 \\
\hline Faculdade privada & 3 & 1 & 2 & 2 \\
\hline Faculdade pública & 1 & 1 & 4 & 1 \\
\hline $\begin{array}{l}\text { Movimento } \\
\text { estudantil }\end{array}$ & 4 & 1 & 2 & 2 \\
\hline $\begin{array}{lr}\text { Outras } & \text { atuações } \\
\text { anteriores } & \text { em } \\
\text { advocacias } & \text { de } \\
\text { causas } & \\
\end{array}$ & 3 & 0 & 6 & 2 \\
\hline Órgãos públicos & 3 & 0 & 3 & 2 \\
\hline Pós-graduação & 4 & 2 & 3 & 3 \\
\hline $\begin{array}{l}\text { Total de } \\
\text { entrevistados }\end{array}$ & 4 & 2 & 6 & 3 \\
\hline
\end{tabular}

Fonte: Elaborado pelos autores.

No quadrante $(A)$ do diagrama estão localizados os advogados paulistas do coletivo AA (SP1 e SP2) e da Conectas Direitos Humanos (SP6), e os dois advogados do CDA/RJ (RJ1 e RJ3). Em comum entre eles, a organização coletiva formal ou informal do trabalho de advogados voltada para a viabilização da própria advocacia como uma forma de ativismo (a advocacia como movimento, seja na defesa da

11 Essa classificação foi desenvolvida a partir de categorias nativas de classificação do grau de vinculação profissional ("orgânicos", "orbitantes" e "articuladores") empregadas por profissionais da Rede Nacional de Advogados e Advogadas Populares (RENAP), verificadas e descritas em Almeida (2016a). 
liberdade de manifestação, seja na defesa genérica de direitos humanos), com possibilidade de ação relativamente independente de interesses ou demandas específicas de movimentos sociais e com alto grau de engajamento nessas organizações, na qualidade de fundadores e/ou coordenadores (advogados orgânicos).

No quadrante (B) está a advogada do Rio de Janeiro (RJ2) que atua dando suporte ao Movimento dos Trabalhadores Sem Teto (MTST), mas cuja atividade profissional é a advocacia particular. Sua trajetória é marcada por engajamentos políticos prévios, mas, por ser de uma geração mais recente, começa na advocacia de causas ao mesmo tempo em que começa na advocacia. Os protestos de junho de 2013 possibilitaram a transformação de uma militância política em um ativismo jurídico, embora eventual.

No quadrante (C) estão os advogados que mantêm dedicação integral ou predominante à advocacia de causas (advogados orgânicos), mas que recusam o protagonismo da advocacia como uma forma de ativismo, subordinando a atuação profissional ao interesse e demandas dos movimentos e à superação de desigualdades entre conhecimento profissional especializado e saber leigo (advocacia para movimentos). São, nesse caso, as advogadas do Centro de Assessoria Popular Mariana Criola (RJ6, RJ7 e RJ8), o advogado do MPL (SP7) e os dois defensores públicos (SP4 e SP5). Se considerarmos os elementos de trajetórias da tabela 2, veremos que um fator distintivo desse grupo em relação aos demais é o da formação em universidades públicas, combinado com a passagem de assessoria jurídica universitária e a experiência em advocacia de causas anterior à atuação nos protestos. Essa constatação nos permite identificar esse grupo de advogados com o perfil, já analisado pela literatura, da chamada advocacia popular no Brasil, seja por sua organização representada pela dedicação exclusiva ou predominante a causas de movimentos sociais, sem pretensão de protagonismo em relação a elas, e de separação ou hierarquização entre saber jurídico e saber leigo (CARLET, 2015; SÁ E SILVA, 2015) -, seja por suas trajetórias, com destaque para o papel da assistência jurídica organizada em universidades públicas como parte da formação para a advocacia de causas (SÁ E SILVA, 2012).

Por fim, no quadrante (D) estão as advogadas RJ4 e RJ5, que possuem outras atividades (atuação em ONG de direitos humanos em um dos casos, tradução e advocacia eventual, no outro), mas que, quando articulam os conhecimentos jurídicos, fazem-no de forma pontual para assessorar os protestos. Nesse quadrante também estão os dois advogados colaboradores do MPL em São Paulo (SP3 e SP8), que mantêm escritórios próprios de advocacia criminal, atuando eventualmente a serviço de movimentos (sendo a atuação de SP3 mais regular e próxima, e a de SP8, mais eventual e pontual).

A análise do perfil profissional dos entrevistados e sua classificação nos termos acima expostos nos permitem levantar a hipótese, a ser aprofundada, de que, apesar da novidade e da 
diversidade do ativismo político de junho de 2013 (BRINGEL; PLEYERS, 2015; TATAGIBA, 2014), a prática da advocacia nos protestos ainda conta com a forte presença da advocacia popular tal qual constituída antes daqueles eventos. Sua conversão aos protestos, entretanto, ainda se dá na atuação de uma clientela diferente daquela habitual de movimentos sociais e em relação de simultaneidade ou colaboração com outras formas de advocacia, muitas das quais emergentes no próprio contexto dos protestos.

\section{A prática da advocacia nos protestos}

Em relação a esse último aspecto, diversos estudos sobre advocacia de causas apontam a necessidade de se compreender essa forma de exercício profissional não apenas em função dos advogados, suas práticas e percepções, mas também da sua relação com os movimentos que formam sua clientela, seja no esforço de construção de uma tipologia de serviços legais de acordo com demandas e movimentos sociais (JUNQUEIRA, 1996), seja na possibilidade de se apreender o papel da interação entre leigos e profissionais na construção de estratégias jurídicas e políticas levadas a cabo conjuntamente por advogados e movimentos (CAMPILONGO, 2000; CARLET, 2015; KRISHNAN, 2006; MCCANN; SILVERSTEIN, 1998).

\section{a) Causas, movimentos e protestos}

Nesse sentido, uma primeira observação deve ser feita, reforçando nossa opção por um conceito ampliado de advocacia de causas, cujas manifestações concretas estudadas, em geral, relacionam a ação política de advogados a movimentos sociais e a causas coletivas. Os eventos de junho de 2013, porém, destacam a centralidade do protesto como ação política que, embora se relacione diretamente com movimentos e causas ${ }^{12}$, possui uma dinâmica própria

12 Segundo Della Porta e Dani (2006), protestos são formas não rotineiras de se afetar processos políticos, sociais e culturais, constituindo-se como parte do repertório de ação política dos movimentos sociais. Segundo esses autores, embora, em geral, o protesto seja um recurso utilizado preferencialmente justo por grupos menos poderosos politicamente, ele permite a articulação de processos de persuasão indireta, mediada pela mídia de massas (que lhes dá visibilidade) e por atores políticos mais poderosos (lideranças políticas, outros grupos e instituições sensibilizadas pela visibilidade da ação política). Jasper (2016) trata movimento social, movimento de protesto e protesto como conceitos quase intercambiáveis, mas admite que nem todo protesto assume a forma de movimento de protesto, que movimentos sociais podem optar por formas diferentes de ação que não o protesto e que o protesto pode ser canalizado por organizações regulares da vida política como os partidos. A distinção entre movimento social como ator político coletivo e protesto como meio de ação, apesar de meramente analítica (em oposição à complexidade da prática política verificada em junho de 2013), é necessária para a reflexão que fazemos sobre 
dentro dos repertórios de ação política e teve peculiaridades importantes no contexto brasileiro deste estudo.

Esse aspecto é importante para a análise das modalidades de advocacia de causas que a pesquisa identificou em protestos ocorridos entre junho de 2013 e janeiro de 2015. Em primeiro lugar, a própria diversidade da infraestrutura dos protestos, baseada em diferentes tipos de organização e em ativismo individual, com baixa presença de movimentos e partidos "tradicionais" (BRINGEL; PLEYERS, 2015; TATAGIBA, 2014), obriga-nos a superar a ideia da advocacia de causas necessariamente como advocacia de movimento, quando entendido como organização coletiva mais ou menos permanente, que pode ou não praticar atos de protestos. A pluralidade, a indefinição e a contradição de causas, associadas a essa diversidade organizativa, por sua vez, dificultam o emprego do conceito de advocacia de causas coletivas. Além disso, o foco de análise nos protestos, e não necessariamente nas causas e nos movimentos, levou-nos inevitavelmente a uma análise da prática criminal da advocacia de causas, fato que problematiza ainda mais as conhecidas oposições entre assistência individual e coletiva, e entre uso técnico, estratégico e alternativo do direito positivo, típicas dos estudos sobre advocacia popular e de causas coletivas (CAMPILONGO, 2000; CARLET, 2015; KRISHNAN, 2006; SÁ E SILVA, 2012). Nesse sentido, vários dos entrevistados relataram a necessidade de uma ação estritamente técnica e consequente da defesa jurídica, diante da urgência e da gravidade das situações de prisões e criminalização, o que sugere uma redução do espaço para o uso alternativo ou transformador do direito.

Talvez tenha sido essa emergência da necessidade de militar por um direito ao protesto o que fez convergir, para um conjunto de práticas semelhantes, pessoas diferentes, com perspectivas diferentes e trajetórias que, apesar de pontos em comum (e as redes pessoais foram muito importantes, tanto no Rio como em São Paulo, para a constituição de uma rede político-jurídica), até então eram distintas. No mesmo sentido, devemos compreender o esforço dos advogados do MPL (SP7 e seu colaborador mais próximo, advogado SP3) em diminuir a importância do direito ao protesto em relação às pautas substantivas de seu movimento, como forma de evitar a sobreposição da questão policial sobre a do transporte público, e do jurídico sobre o político, a partir de uma concepção, compartilhada entre ambos, de advocacia para movimentos.

b) Instituições de justiça e segurança

As instituições de justiça e segurança mais referenciadas pelas narrativas dos entrevistados são as polícias militar e civil. Isso se deve ao predomínio da ação repressiva imediata do Estado em relação aos

a utilidade dos conceitos de advocacia de causas coletivas e de advocacia de movimentos para a compreensão da advocacia de causas em protestos.

Caderno Eletrônico de Ciências Sociais, Vitória, v. 4, n. 2, pp. 5-28, 2016 
protestos, por meio da ação policial ostensiva e, secundariamente, ao papel da Polícia Civil na condução de inquéritos penais. Constatamos, na fala dos entrevistados e em outras informações por eles disponibilizadas, a percepção de que a estratégia estatal foi a da repressão imediata, incluindo prisões sem fundamentos e sem consequências futuras (as prisões consideradas arbitrárias ou "para averiguação"), e sem, necessariamente, uma estratégia judicial de responsabilização desenvolvida na mesma proporção. ${ }^{13}$

No caso da Polícia Civil, os inquéritos são apontados como estratégias de monitoramento e desmobilização dos protestos no tempo. Um indício a reforçar essa percepção é o fato de haver, ainda, inquéritos em andamento desde então, como extensos inquéritos envolvendo grande número de manifestantes (o inquérito penal 1/2013 de São Paulo e o chamado "inquérito-mãe" do Rio de Janeiro), nos quais os entrevistados enxergam uma motivação política ainda mais aguda dos órgãos de segurança. No Rio de Janeiro, há informações de que, por um lado, a repressão durante os protestos pouco produziu em termos de ações penais - os detidos eram liberados após pressão dos advogados e mediante levantamento e exame de FAC (Ficha de Antecedentes Criminais) - , mas, por outro, as escutas telefônicas ao longo dos protestos possibilitou levar a repressão ao nível judicial em alguns casos, como na prisão preventiva de 23 "participantes habituais" em protestos por considerá-los "perigosos" na véspera da final da Copa do Mundo de 2014, ainda vinculados a um "processomãe". No caso de São Paulo e, ao menos no que se refere ao MPL, apesar de toda a repressão e do grande número de prisões noticiadas pela imprensa e confirmadas pelos advogados, a ação policial resultou em apenas quatro inquéritos (um deles arquivado) e duas ações penais (uma que resultou em absolvição e outra, em suspensão condicional do processo), conforme informações prestadas pelo advogado SP7 (com exceção do já citado inquérito 1/2013, apenas recentemente arquivado).

Contudo, é preciso notar que o predomínio da ação policial aparece não somente como uma opção do Estado, mas também dos próprios advogados. Destes, alguns optaram pela atuação apenas na mediação, na denúncia ou na contenção da ação policial e no acompanhamento imediato de manifestantes presos, mas não em uma atuação que se estendesse ao âmbito do inquérito policial e de eventuais ações penais. Essa opção estratégica parece ter sido mais evidente entre os advogados orgânicos da advocacia como movimento no Rio de Janeiro e em São Paulo. Também aparece na fala do advogado orgânico do MPL em São Paulo, que relatou que, após 2013, e visando a nova jornada de protestos de 2015 pela redução da tarifa de transporte, optou-se por articular assessoria jurídica apenas para

${ }^{13}$ Sobre a prevalência da ação policial no conjunto de respostas estatais aos protestos em São Paulo, ver Almeida (2016b).

Caderno Eletrônico de Ciências Sociais, Vitória, v. 4, n. 2, pp. 5-28, 2016 
as prisões e por repressão imediata nos protestos, mas com a orientação de que ativistas que tivessem desdobramentos judiciais de sua situação procurassem a Defensoria Pública. Essa opção foi justificada pelos custos de tempo e energia para a articulação e manutenção da rede de advogados colaboradores durante toda a tramitação de uma ação penal, bem como pela mudança de conjuntura política que tornaria difícil um engajamento de colaboradores tão intenso quanto o que ocorreu em 2013. É razoável imaginar que, nessa concepção, se o que está em jogo é um "direito ao protesto" e a ação policial incide para desmobilizar ou atrapalhar manifestações, é nessa esfera que esse tipo de advocacia privilegia suas ações.

Já os advogados orgânicos e colaboradores deram grande ênfase em suas narrativas à atuação da Polícia Civil. Esses dados sugerem uma estratégia de contenção da criminalização dos protestos ainda no nível da investigação policial, combinada com o já alegado interesse dos órgãos de segurança em manter investigações como forma de monitoramento e desmobilização. Faz sentido imaginar que a relação desses advogados se dá em outra esfera, a das instituições e dos movimentos, estabelecendo uma atuação necessariamente mais perene.

A atuação da Defensoria Pública estadual aparece de forma muito mais recorrente nas narrativas de advogados paulistas do que dos cariocas. Isso evidencia objetivamente as diferentes inserções dessa instituição nos protestos nas duas cidades. No Rio, o Defensor Geral na época mantinha uma linha corporativa de atuação, tendo destacado em sua campanha que "A Defensoria é para os Defensores". Algumas das entrevistas (RJ4 e RJ8) fazem menção a uma atuação no mínimo hesitante da instituição, recusando pedidos de autorização para defensores atuarem durante os protestos. Apenas quando era necessário um trato direto entre advogados e defensores é que a relação se mostrava amistosa, muitos dos quais já conhecidos por outras oportunidades. Relações, portanto, muito mais pessoais/profissionais que institucionais.

Em São Paulo, houve uma mobilização efetiva da instituição na defesa de manifestantes e na tomada de outras ações para garantir a viabilização dos protestos e combater a repressão policial - ação civil pública contra o uso de balas de borracha pela polícia; habeas corpus preventivo para participação de ativistas em protestos; pedido de apuração de abusos policiais junto ao Ministério Público -, como demonstram as falas dos próprios defensores públicos entrevistados, bem como de outros advogados entrevistados e que reconhecem a atuação daquele órgão. Mais do que isso, os advogados orgânicos e colaboradores do MPL, bem como o advogado da Conectas Direitos Humanos, declararam estratégias articuladas de ação conjuntamente com a Defensoria Pública.

Essa situação se inverte quando analisamos a percepção dos entrevistados em relação à atuação da $O A B$ nos protestos. Em São Paulo, a atuação da OAB foi considerada tímida, ausente, quando não 
contrária à atuação dos advogados de causas (alguns entrevistados falaram em atuação "vergonhosa" da Ordem). Também houve relatos, de alguns advogados do coletivo Advogados Ativistas, de assédio por parte de membros das Comissões de Segurança Pública e de Defesa da Advocacia da $O A B$, no sentido de dificultar sua ação nas delegacias e de questionar a prestação de serviços gratuitos.

Por outro lado, no Rio de Janeiro, a OAB teve papel central na articulação da advocacia de causas e nas bases operacionais da relação entre advogados orgânicos e advogados colaboradores para atuação em protestos, mesmo quando essa articulação foi objeto de críticas por parte de advogados. Isso se deve à centralidade da CAARJ na articulação do $C D A / R J$ e da rede de colaboração e atuação nos protestos, mas também precisa ser percebido como um movimento de aproximação do órgão de classe para se legitimar perante representados e população.

\section{c) Mídias tradicionais e alternativas}

Mesmo entre advogados que se disseram críticos do protagonismo midiático da advocacia no que diz respeito aos movimentos sociais - que é o caso especialmente dos advogados orgânicos da advocacia para movimentos, ou seja, dos advogados populares, mas também de seus colaboradores -, a relação com as mídias é vista como importante para a atuação nos protestos, seja para denunciar abusos policiais, seja para a repercussão de suas ações de contestação da repressão e dos abusos policiais. A intensidade das novas tecnologias de informação e comunicação, em comparação com ciclos anteriores de protestos, reforça essa importância. No caso dos Advogados Ativistas de São Paulo, a relação com as mídias se confunde com uma atuação assumidamente de mídia, sendo a produção de conteúdo e a atuação na internet assumida pelos entrevistados desse grupo como sua atividade central. Um deles chegou a identificar a atuação do coletivo como parte do movimento de "mídia livre", "mídia alternativa" ou "midiativismo", e sabemos que, após junho de 2013, aqueles profissionais se engajaram na construção e na manutenção de um site de notícias e artigos voltados para comunidade jurídica.

\section{d) Organicidade e liderança}

Essa questão da relação com a mídia está ligada à própria interação dos advogados com os movimentos em termos de protagonismo e entre saber técnico e ação política. Advogados para movimentos, orgânicos ou colaboradores tendem a repetir o discurso típico da advocacia popular de negação do protagonismo ou da superioridade da advocacia sobre a luta política. Esse fato se reflete, nas entrevistas, em suas narrativas sobre a construção de estratégias conjuntas, a submissão de suas estratégias jurídicas a decisões políticas dos movimentos e as negativas dos profissionais em darem entrevistas à imprensa. Já entre profissionais da advocacia como movimento são mais comuns as menções a um papel de liderança e 
organização do movimento social a partir da expertise jurídica, transmitida na forma de orientações ou de treinamento em questões jurídicas e de segurança para protestos. Por outro lado, esse papel acontece muito mais em relação ao pluralismo e à pulverização do ativismo de junho de 2013 do que em relação a movimentos já consolidados e organizados antes daqueles eventos. Em outras palavras, podemos afirmar que o outro lado da organicidade de uma advocacia que vê a si mesma como movimento é a ausência de relações mais orgânicas com movimentos sociais organizados.

Por fim, devemos considerar o papel da experiência profissional e do aprendizado para atuação em protestos. Tanto em entrevistas em São Paulo quanto no Rio de Janeiro, com advogadas e advogados mais antigos não apenas na advocacia, mas também na militância política (em especial, com um passado ou uma prática atual na advocacia popular), ficou presente a impressão de que os novos ativistas jurídicos - que iniciaram uma atuação política e/ou jurídica nas manifestações a partir de junho de 2013 - não possuíam as ferramentas práticas de atuação, mobilização e organização do trabalho, tanto por pouca intimidade com o tipo de trabalho a ser desempenhado (lidar com delegacias e policiais militares) quanto pela pouca experiência em lidar com questões e grupos/atores políticos.

Essa percepção se juntava à crítica dos profissionais da advocacia para movimentos às relações com a mídia e ao protagonismo de profissionais da advocacia como movimento. Ela foi confirmada pela observação de dois protestos em São Paulo em janeiro de 2015, nos quais a atuação de advogados da advocacia como movimento se dava de maneira mais aguerrida, conflituosa e explosiva, especialmente no trato com a polícia e no uso imediato da imprensa para denúncia de abusos, do que a dos advogados para movimentos, que mantinham postura mais serena e menos conflitiva, evitando a intervenção logo no momento da prisão e deixando seu trabalho principal para a delegacia. Por outro lado, em praticamente todas as entrevistas, foi possível perceber referências a um aprendizado profissional rápido, intenso e interacional, decorrente da verificação em prática das estratégias policiais e judiciais e da necessidade de se alterar práticas de ativismo e de defesa jurídica de ativistas como reação ensaiada a cada novo ato de protesto das jornadas de junho de 2013 e dos protestos que se seguiram no mesmo ciclo.

\section{Considerações finais}

A análise das entrevistas realizadas nos permite identificar que a advocacia nas manifestações em São Paulo e no Rio de Janeiro nos ciclos de protestos de junho de 2013 representou, em certa medida, a diversidade do próprio ativismo daquele ciclo. Os diferentes grupos e perfis profissionais identificados refletem, nesse sentido, a pluralidade de atores políticos que impulsionaram as jornadas de junho.

Os advogados que classificamos como profissionais de uma advocacia para movimentos, e que guardam muitas correspondências 
com a chamada advocacia popular, tiveram papel central na defesa de manifestantes e na contestação da repressão estatal. Isso demonstra a conversão de formas já consolidadas da advocacia de causas no Brasil ao contexto específico dos protestos.

Ao lado deles, profissionais que constroem sua própria prática profissional como uma forma de ativismo, ou seja, a advocacia como movimento, também se destacaram nos protestos de 2013. É importante notar que muitos deles iniciaram esse ativismo nas próprias jornadas de junho, não necessariamente como advogados, mas muitas vezes como militantes nos protestos.

Também há, nesse grupo, a advocacia de direitos humanos praticada por organizações não governamentais, capaz de articular ações e demandas independentemente de uma "clientela" de movimentos sociais. Esse encontro forçado de instituições (em especial $\mathrm{OAB}$, no Rio de Janeiro, e Defensoria Pública, em São Paulo) e personagens com trajetórias e perspectivas diferentes produziu, em alguns momentos, cooperação e constituição de saberes e práticas jurídicas (e parajurídicas) na atuação em protestos; em outros momentos, proporcionou choques e, mesmo, rupturas, frutos exatamente de uma diversidade de concepções sobre o papel da advocacia.

Em termos analíticos e metodológicos, a própria construção dessa tipologia é uma contribuição da nossa pesquisa para os estudos sobre advocacia de causas, seja pela já mencionada relação entre advocacia e movimentos, seja pela identificação das redes de articulação entre profissionais orgânicos e profissionais colaboradores. Um ponto interessante a ser investigado com maior profundidade e em perspectiva comparada é a dinâmica de ativação e desativação dessas redes em função de demandas específicas, bem como as formas de recrutamento e as destinações posteriores dos advogados colaboradores. Saber como se deu a dinâmica de relação entre advocacia e causas após o ciclo de protestos permitirá compreender um processo de potencialização ou mesmo de entrada na política (em diversas acepções que a expressão assume nos casos encontrados) pelo direito.

A especificidade do protesto como forma de ação política também traz um elemento novo e importante para a análise da advocacia de causas por vários motivos: pela possibilidade de que o próprio protesto forme politicamente novos advogados de causas, pela dinâmica específica e circunstancial das redes de relações entre orgânicos e colaboradores e pelos desafios impostos à prática profissional dos advogados. Em relação a esse último aspecto, destaca-se a atuação criminal individualizada (em detrimento das ações civis e coletivas), a maior interação com instituições de segurança (polícias) do que de Justiça (Judiciário e Ministério Público) e o menor espaço assumido pelos profissionais para uma prática alternativa ou transformadora do direito, diante da urgência e da gravidade da situação de prisão e criminalização. Sobre esse ponto, destaca-se, ainda, na análise das 
entrevistas, o papel da experiência prévia na advocacia em geral, e na advocacia de causas em especial, para a construção das estratégias jurídicas e políticas de atuação nos protestos, bem como o aprendizado desenvolvido pelos próprios advogados ao longo de um ciclo de protestos, em função do dinamismo e da imprevisibilidade desse tipo de ação política.

Se, por um lado, as manifestações do ciclo iniciado em junho de 2013 guardavam especificidades (entre elas, a multiplicidade aparente de agendas), por outro lado, e a partir da repressão empregada, mostraram convergência em um ponto: a centralidade do protesto como forma de ação e da rua como arena política. E a advocacia de causas, articulada nesses episódios, retomou ou desenvolveu redes, práticas e saberes aplicáveis a esse contexto específico. Nesse sentido, em comum entre esses diferentes grupos que se engajaram nos protestos por meios e motivações, podemos retomar a ideia de uma advocacia de rua (RIBAS; NEURAUTER, 2014), seja quando a defesa do direito ao protesto é, em si, uma causa (como é para a advocacia como movimento), seja quando ela é uma atividade demandada por causas de fundo que não se confundem imediatamente com o direito ao protesto (como é o caso da advocacia para movimentos).

É necessário que pesquisas futuras identifiquem como esse conjunto de redes, saberes e práticas pode ser novamente aplicado em um ativismo jurídico posterior ao período e aos protestos estudados, especialmente se percebermos, nos relatos coletados, que o sistema de justiça operou durante esses protestos para desmobilizá-los: não apenas as instituições policiais criaram e aplicaram mecanismos de dispersão - detenção sem motivos, condução para delegacia fora da área pela polícia militar, verificação de antecedentes criminais pela polícia civil -, mas também as instituições do sistema de justiça agiram para produzir dificuldades aos protestos - decisões de prisões preventivas, de proibição de protestos ou de uso de máscaras. A intensidade daquele ciclo de manifestações, por vezes com mais de um ato ocorrendo na mesma semana, também precisa ser considerada como uma característica do momento, a qual interfere positivamente na intensificação das relações entre atores, e negativamente, pelo desgaste causado por essa mesma dinâmica. O aprofundamento das pesquisas sobre a advocacia de causas atuante no ciclo de protestos iniciado em junho de 2013 em perspectivas comparadas, espacial e temporalmente, pode nos ajudar a compreender as formas de mobilização do direito tanto para a repressão de ações políticas contenciosas, quanto para a resistência a essas práticas estatais pelos movimentos sociais e advogados de causas.

\section{Referências bibliográficas}

ALMEIDA, F. 2010. Inherited Capital and Acquired Capital The Sociopolitical Dynamics of Producing Legal Elites. Brazilian Political Science Review, v. 4, n. 2, pp. 32-60. 
. 2012. Do profissional-docente ao docente profissional: a valorização simbólica dos títulos acadêmicos e da experiência docente no campo jurídico brasileiro. In: CARVALHO, E. M. et al. (Org.). Representações do Professor de Direito. Curitiba: CRV.

. 2016a. Advogados e política: notas a partir da observação de um encontro de advogados populares no início dos anos 2000. Revista de Estudos Empíricos em Direito, v. 3, n. 2, pp. 135-148.

. 2016b. Ordem, direito e política: do que se fala quando se fala em "criminalização dos movimentos sociais"? Anais do X Encontro da $A B C P$. Belo Horizonte.

ALMEIDA, F.; NORONHA, R. 2015. Advogando nas ruas: advocacia em protestos urbanos em São Paulo e no Rio de Janeiro (2013-2015). Anais do $39^{\circ}$ Encontro Anual da Anpocs. Caxambu.

BRINGEL, B.; PLEYERS, G. 2015. Junho de 2013... dois anos depois. Nueva Sociedad - especial em português, pp. 4-17.

CAMPILONGO, C. F. 2000. Assistência jurídica e advocacia popular: serviços legais em São Bernardo do Campo. In: O direito na sociedade complexa. São Paulo: Max Limonad.

CARLET, F. 2015. Advocacia Popular: práticas jurídicas contrahegemônicas no acesso ao direito e à justiça no Brasil. Revista Direito e Práxis, v. 6, n. 10, pp. 377-411.

CISNEROS PUEBLA, C. A. 2003. Analisis cualitativo asistido por computadora. Sociologias, n. 9, pp. 288-313.

DELLA PORTA, D.; DIANI, M. 2006. Social Movements: an introduction. 2. ed. Malden: Blackwell.

ENGELMANN, F. 2006a. Internacionalização e ativismo judicial: as causas coletivas. Lua Nova, n. 69, pp. 123-146.

ENGELMANN, F. 2006b. Sociologia do campo jurídico: juristas e usos do direito. Porto Alegre: Sergio Antonio Fabris.

ETIENNE, M. 2005. The Ethics of Cause Lawyering: an Empirical Examination of Criminal Defense Lawyers As Cause Lawyers. Journal of Criminal Law \& Criminology, v. 95, n. 4, pp. 1195-1260.

HALLIDAY, T. C. 1999. The politics of lawyers: an emerging agenda. Law \& Social Inquiry, v. 24, n. 4, pp. 1007-1011.

JASPER, J. M. 2016. Protesto: uma introdução aos movimentos sociais. Rio de Janeiro: Zahar.

JUNQUEIRA, E. B. 1996. Naranjas y manzanas: dos modelos de servicios legales alternativos. El otro derecho, v. 7, n. 21, pp. 27-57.

. 2002. Los abogados populares: en busca de una identidad. El otro derecho, n. 26-27, p. 193-227.

KRISHNAN, J. K. 2006. Lawyering for a cause and experiences from abroad. California Law Review, v. 94, n. 2, pp. 575-615.

MCCANN, M.; SILVERSTEIN, H. 1998. Rethinking Law's "Allurements". In: SARAT, A.; SCHEINGOLD, S. (Org.). Cause Lawyering: Political Commitments and Professional Responsibilities. New York: Oxford University Press. 
SÁ E SILVA, F.. 2012. Lawyers and Governance in a Globalizing World: Narratives of "Public Interest Law" Across the Americas. Tese $(\mathrm{PhD})$.Northeastern University. - 2015. Hegemonia e contra-hegemonia na globalização do direito: a "advocacia de interesse público" nos Estados Unidos e na América Latina. Revista Direito e Práxis, v. 6, n. 10, pp. 310-376.

SCHEINGOLD, S. A. 1988. Radical Lawyers and Socialist Ideals. Journal of Law and Society, v. 15, n. 1, pp. 122-138.

TATAGIBA, L. 2014. 1984, 1992 e 2013. Sobre ciclos de protestos e democracia no Brasil. Política \& Sociedade, v. 13, n. 28, pp. 35-62.

VÉRTIZ, F. 2013. Los abogados populares y sus prácticas profesionales. Hacia una aplicación práctica de la crítica jurídica. Crítica Jurídica, n. 35, pp. 251-274. 